\title{
Relationship between Tei Index and Prognosis in Patients with Non ST Segment Elevation Myocardial Infarction
}

\author{
Sabri Seyis $^{1 *}$, Turkay Ozcan ${ }^{2}$ \\ ${ }^{1}$ Istinye University Liv Hospital, Department of Cardiology, Istanbul, Turkey \\ ${ }^{2}$ Mersin University Faculty of Medicine, Department Of Cardiology, Mersin, Turkey \\ "Corresponding Author: Sabri Seyis, Istinye University Liv Hospital, Department of Cardiology, Istanbul, \\ Turkey, Tel: +905332472009; E-mail: sabriseyis@yahoo.com
}

Received: 14 October 2017; Accepted: 23 October 2017; Published: 27 October 2017

\begin{abstract}
Background and Objective: It is important to make risk stratification for patients with non ST segment elevation MI to reduce mortality, reinfarctions and to improve prognosis. Through the echocardiographic parameters; ejection fraction does not reflect diastolic functions. Tei index is a new parameter representing both left ventricular systolic and diastolic functions at the same time. The aim of this study is to determine the relationship between Tei index and prognosis in patients with non ST segment elevation MI.
\end{abstract}

Method: Fifty patients (mean age: 60.1 \pm 11 ) with non ST segment elevation MI were included to our study. All the patients were given standard care and managed according to well accepted guidelines. Clinical and laboratry data were collected during hospitalization. Echocardiographic examinations were done on the hospitalization day and 3 months after discharge. Tei index and other echocardiographic examinations were evaluated.

Results: Mean value of the index through the patient group was $0.39 \pm 0.03$, whereas it was $0.59 \pm 0.09$ through control group (p:0.001). Through the follow up 14 patients (28\%) had major cardiac adverse events (MACE). Tei index of deaths were significantly higher than alives ( $0.73 \pm 0.005$ vs $0.58 \pm 0,09, \mathrm{p}: 0.002)$. Compared to uncomplicated patients, the mean Tei index was significantly higher in patients with complications $(0.71 \pm 0.0$ vs $0.55 \pm 0.07$, p:0.001). Death was observed in 4 patients (14.2\%) in Tei index 0.60 group whereas no death was seen in Tei index $<0.60$ group (p:0.001). Heart failure was observed in 10 patients (35.7\%) in Tei index 0.60 group compared to only 2 patients ( $9 \%$ ) in Tei index $<0.60$ group (p:0.001). After 3 months, Tei index values were decreased in both groups of patients. 
Conclusion: It is concluded that Tei index can be used as a predictive tool for adverse cardiac events in patients with non ST segment elevation MI.

Keywords: Non-ST segment elevation myocardial infarction; Tei index ( myocardial performance index); Diastolic dysfunction

\section{Introduction}

Risk assessment is important to prevent myocardial infarction (MI), recurrent coronary events or death, and to improve prognosis in patients suffering acute coronary syndrome (ACS) with non-ST-segment elevation. Systolic and diastolic dysfunction frequently coexist in MI, even though both isolated systolic and isolated diastolic dysfunction can be identified. The development of congestive heart failure (CHF) after acute MI has been shown to be significantly related to both left ventricular (LV) systolic and LV diastolic dysfunction [1-4]. The duration of diastole is an important determinant of myocardial perfusion [5], and the ratio of the diastolic to the systolic pressure-time index is used to assess a relationship between subendocardial oxygen supply and demand [6]. Ejection fraction (EF), which is an indicator of systolic function, has been the most studied and accepted parameter among the echocardiographic parameters used for risk assessment. However, EF is inadequate to evaluate systolic and diastolic functions together.

The Tei index, which is measured by Doppler echocardiography, is used to evaluate both systolic and diastolic function. It is and not affected by the geometric structure of the ventricle [7].

The data associated with the Tei index in patients who developed CHF and other complications during and after hospitalization due to acute ST-elevation MI are contradictory and there are publications suggesting the prognostic value of Tei index [8-9].

Our aim in this study is to perform echocardiographic Tei index measurements in patients admitted to our clinic due to non-ST-segment elevation myocardial infarction (NSTEMI) and to investigate the relationship between the Tei index and mortality, CHF, ventricular dilatation, and prognosis during and after hospitalization.

\section{Materials and Methods}

\subsection{Patient Inclusion}

We included 50 patients who admitted to the emergency department and evaluated at the department of cardiology of the Mersin University Hospital with the diagnosis of NSTEMI. The patients did not have a history of previous MI. The diagnosis of NSTEMI was based on the presence of typical angina pain that lasts at least 30 minutes and a troponin level of $>0.1 \mathrm{ng} / \mathrm{ml}$. Patients with ST-elevated MI or other diagnoses were excluded after serial ECG evaluations. A group of 30 healthy volunteers without previously known cardiovascular disease was included in the 
study as the control group.

Patients with atrial fibrillation, pacemaker rhythm, aortic stenosis, and patients whose echocardiographic image quality was inadequate were also excluded. The approval for the study was obtained from the local ethics committee. All individuals participating in the study were informed about the procedures and their consents were obtained.

\subsection{Data Collection}

The data obtained from the patients were recorded on the data registration form for later evaluation. The data registration form was essentially composed of four parts.

The first part included the findings of physical examination and ECG during the admission to the hospital along with the questions about basic clinical features such as age, sex, and the risk factors for coronary artery disease (CAD).

The second part included the medical treatments given in the hospital, the laboratory parameters such as the highest troponin and C-responsive protein (CRP) levels, and the data related to the echocardiographic examinations.

The third part noted the major adverse cardiovascular events (recurrent MI, hospitalization, development of heart failure, death, etc.).

The fourth section included the echocardiographic parameters measured after 3 months.

\subsection{Echocardiographic Evaluation}

The echocardiographic and Doppler measurements were performed using a PHILIPS HD11XE device within the first 24 hours of patients' admission to the cardiology clinic and these measurements were repeated after 3 months in surviving patients.

The left ventricular end-systolic and diastolic volumes (LVESV and LVEDV) were calculated from the apical fourchamber images and the left ventricular ejection fraction was calculated using Simpson method.

The Tei index was obtained by using the ejection time obtained by Doppler echocardiography, isovolumic contraction time and isovolumic relaxation time (Figure 1). 


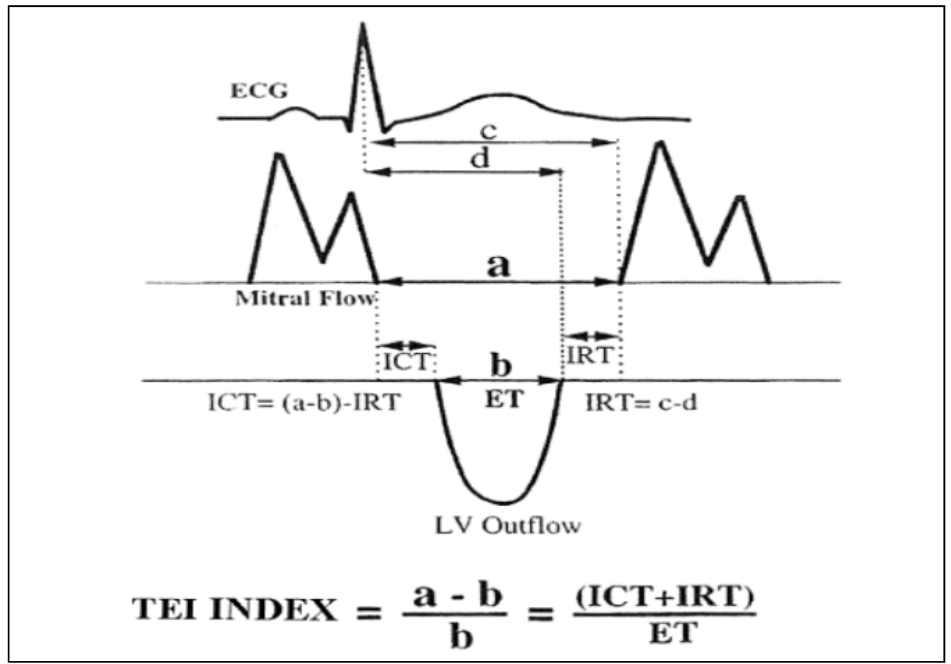

Figure 1: The calculation of the Tei index

The normal value of the Tei index is $0.28 \pm 0.04$ for the right ventricle and $0.39 \pm 0.05$ for the left ventricle [3]

The records obtained by placing the "sample volume" just below the aortic valve, that is the left ventricular outflow tract, in the apical five-chamber view were used in the calculation of the ejection time. The records obtained by placing the "sample volume" between the aortic and mitral valves in the apical five-chamber view were used in the calculation of the isovolumic relaxation and contraction times. All measurements were repeated three times and their averages were used for analyses.

To trace mitral flow, the recordings were obtained by placing the "sample volume" as perpendicular to the tip of the mitral valve as possible in the apical four-chamber view. The long axis images were used to calculate the left ventricular diameters.

\subsection{Statistical analysis}

Statistical analyses were performed using SPSS (Statistical Package for Social Science) for Windows 13.0. Statistical summary tables were prepared to present means and standard deviations for the variables included in the analysis. The Shapiro-Wilk test was used to confirm whether the measured values had normal distribution or not. Corresponding parametric or non-parametric tests were used for the comparisons of the values that do or do not fit the normal distribution. Student's t-test was used to compare the normally distributed values in two independent groups; Mann-Whitney U test was used for those that were not normally distributed. Paired-samples t-test and Wilcoxon Sign test were used to evaluate the differences between the first and $3^{\text {rd }}$ month echo data of the subjects based on the distribution pattern. Chi-squared $\left(\chi^{2}\right)$ analysis was used to analyze categorical data. The statistical significance was set at $p<0.05$. 


\section{Results}

A group of 50 patients (35 male (70\%) and 15 female (30\%)) with acute NSTEMI diagnosis were included in the study along with 30 healthy individuals (67\% male) without any known cardiovascular disease. The characteristics of the patient and control groups are presented in Table 1.

\begin{tabular}{|l|l|l|l|l|l|}
\hline & $\begin{array}{l}\text { Patient Group } \\
\mathrm{n}=50\end{array}$ & $\%$ & $\begin{array}{l}\text { Control Group } \\
\mathrm{n}=30\end{array}$ & $\%$ & $p$ value \\
\hline Age & $60.1 \pm 11.3$ & & $59.5 \pm 6.9$ & & $\mathrm{AD}$ \\
\hline $\begin{array}{l}\text { Gender } \\
\text { (Male/Female) }\end{array}$ & $35 / 15$ & $70 / 30$ & $20 / 10$ & $67 / 33$ & $\mathrm{AD}$ \\
\hline Hypertension & 38 & 76 & 8 & 26 & 0.001 \\
\hline Smoking & 24 & 48 & 6 & 20 & 0.001 \\
\hline Diabetes Mellitus & 16 & 32 & 3 & 10 & 0.001 \\
\hline
\end{tabular}

Table 1: Demographic characteristics of the patient and control groups.

There was a significant difference in echocardiographic characteristics between the patient and control groups (Table 2). Tei index was $0.39 \pm 0.03$ in the control group and $0.59 \pm 0.09$ in the patient group $(p=0.001)$. Among those without hypertension, Tei index was still higher in the patient group compared with the control group: $0.58 \pm 0.08$ and $0.37 \pm 0.02$, respectively $(p=0.001)$. Likewise, when patients with DM were excluded from the patient and control groups, Tei index value was still significantly higher in the patient group compared with the control group: $0.56 \pm 0.07$ and $0.39 \pm 0.03$, respectively $(p=0.001$ ).

\begin{tabular}{|l|l|l|l|}
\hline & $\begin{array}{l}\text { Patient Group } \\
\mathrm{n}=50\end{array}$ & $\begin{array}{l}\text { Control Group } \\
\mathrm{n}=30\end{array}$ & $p$ value \\
\hline E/A Ratio & $0.93 \pm 0.46$ & $0.90 \pm 0.41$ & 0.72 \\
\hline EDT (ms) & $169.8 \pm 31.0$ & $193 \pm 47.7$ & 0.009 \\
\hline IVCT (ms) & $62.9 \pm 10.8$ & $42.0 \pm 4.4$ & 0.001 \\
\hline IVRT (ms) & $88.2 \pm 7.8$ & $73.6 \pm 6.5$ & 0.001 \\
\hline ET (ms) & $256.7 \pm 38.7$ & $304 \pm 17.3$ & 0.001 \\
\hline EF (\%) & $48.5 \pm 11.6$ & $60.7 \pm 5.8$ & 0.001 \\
\hline Tei index & $0.59 \pm 0.09$ & $0.39 \pm 0.03$ & 0.001 \\
\hline
\end{tabular}

Table 2: Echocardiographic characteristics of the patient and control groups.

EDT: Ejection deceleration time, EF: Ejection fraction, ET: Ejection time, IVCT: Isovolumetric contraction time, IVRT: Isovolumetric relaxation time 
There was no difference between the medical treatments given to the patient group (Table 3 ).

\begin{tabular}{|l|l|l|l|l|}
\hline Tei index & \multicolumn{2}{|l|}{$<$} & $\geq 0.60$ \\
\hline & $\begin{array}{l}\text { Treated } \\
\mathrm{n}(\%)\end{array}$ & $\begin{array}{l}\text { Non-treated } \\
\mathrm{n}(\%)\end{array}$ & $\begin{array}{l}\text { Treated } \\
\mathrm{n}(\%)\end{array}$ & $\begin{array}{l}\text { Non-treated } \\
\mathrm{n}(\%)\end{array}$ \\
\hline Clopidogrel & $12(54)$ & $10(46)$ & $16(57)$ & $12(43)$ \\
\hline Aspirin & $22(100)$ & $0(0)$ & $27(96)$ & $1(4)$ \\
\hline Heparin & $14(63)$ & $8(37)$ & $16(57)$ & $12(43)$ \\
\hline DMAH & $8(37)$ & $14(63)$ & $12(43)$ & $16(57)$ \\
\hline Tirofiban & $3(13)$ & $19(87)$ & $4(14)$ & $24(86)$ \\
\hline$\beta$-blocker & $19(86)$ & $3(14)$ & $24(85)$ & $4(15)$ \\
\hline ACEI/ARB & $20(90)$ & $2(10)$ & $27(96)$ & $1(4)$ \\
\hline Statin & $21(95)$ & $1(5)$ & $26(93)$ & $2(7)$ \\
\hline
\end{tabular}

Table 3: Comparison of the medical treatments given to those in the patient group (in terms of the Tei index).

LMWH: low molecular weight heparin, ACEI: angiotensin-converting enzyme inhibitor, ARB: angiotensin receptor blocker

During the follow-up period, 14 subjects in the patient group (28\%) developed major adverse cardiovascular events (MACE). Heart failure (NYHA class II-IV) occurred in 12 patients (24\%); ventricular tachycardia/fibrillation in 2 (4\%); pacemaker-requiring significant bradycardia in $1(2 \%)$; repeated hospitalization in 5 (10\%); and death in 4 patients $(8 \%)$.

The mean EF value of the deceased patients was $33 \% \pm 2 \%$ while that of the surviving patients was $49.8 \% \pm 11 \%$ $(p=0.004)$. The mean Tei index of the deceased patients was $0.73 \pm 0.005$ while it was $0.58 \pm 0.09(p=0.002)$ for the surviving patients. Deceleration time was also significantly shorter in the deceased patients: $130 \pm 14$ msn vs. $173 \pm 29$ $\operatorname{msn}(p=0.007)$ (Table 4).

\begin{tabular}{|l|l|l|l|}
\hline Death & No & Yes & $p$ value \\
\hline Tei index & $0.58 \pm 0.09$ & $0.73 \pm 0.005$ & 0.002 \\
\hline EF (\%) & $49.8 \pm 11$ & $33 \pm 2$ & 0.004 \\
\hline EDT (msn) & $173 \pm 29$ & $130 \pm 14$ & 0.007 \\
\hline
\end{tabular}

Table 4: Comparison of Tei index, the EF, and the EDT for the surviving patients and the deceased patients. There was a significant difference between the patients who developed MACE and those did not in terms of the Tei index: $0.71 \pm 0.01$ and $0.55 \pm 0.07$, respectively $(p=0.001)$ (Table 5). 


\begin{tabular}{|l|l|l|l|}
\hline & MACE developed $(\mathrm{n}=14)$ & $\begin{array}{l}\text { MACE not developed } \\
(\mathrm{n}=36)\end{array}$ & $p$ value \\
\hline Tei index & $0.71 \pm 0.01$ & $0.55 \pm 0.07$ & 0.001 \\
\hline EF (\%) & $35.6 \pm 6.3$ & $53.5 \pm 9.0$ & 0.001 \\
\hline
\end{tabular}

Table 5: Comparison of the Tei index and the EF in patients who developed MACE and those who did not.

Previous studies have shown that patients with Tei indices above 0.60 are more likely to develop heart failure and have a worse prognosis (10-12).

The patients with Tei indices $<0.60$ and those $\geq 0.60$ based on the echocardiographic measurements at admission were compared in terms of occurrence of MACE. In the patient group with high Tei index $(\geq 0.60), 4$ patients died $(14.2 \%)$ and 10 patients had heart failure (35.7\%). In the patient group with low Tei index $(<0.60)$, death was not observed ( $0 \%)$ and only 2 patients had heart failure ( $9 \%)(p=0.001$ for both).

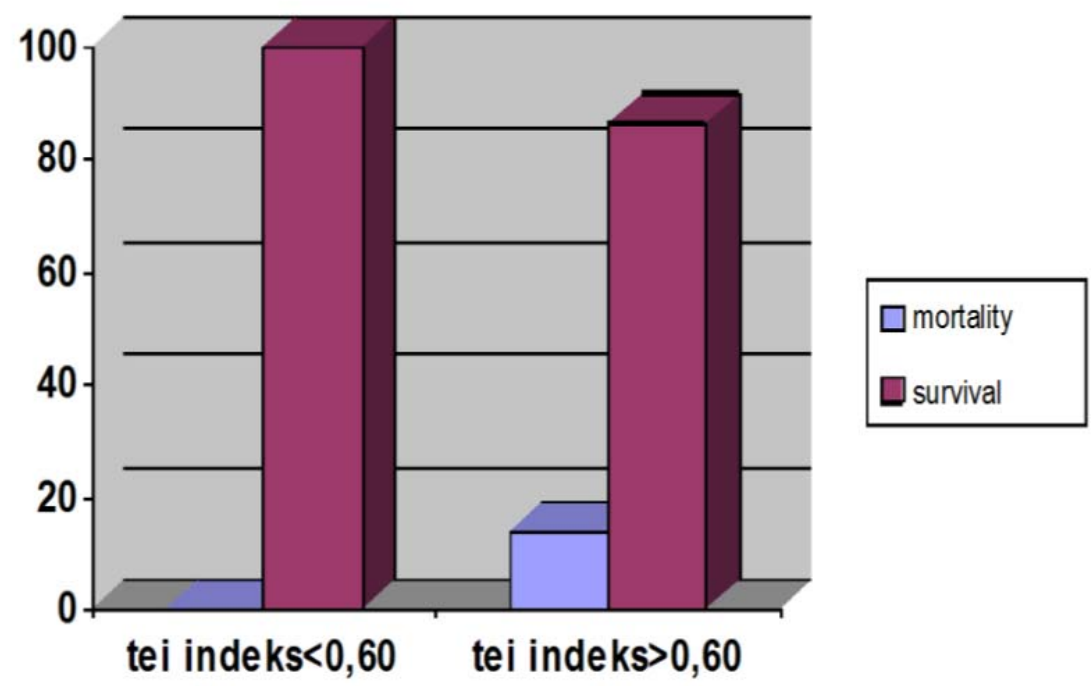

Figure 2: Comparison of mortality in patient groups with Tei index $<0.60$ and $\geq 0.60$. 


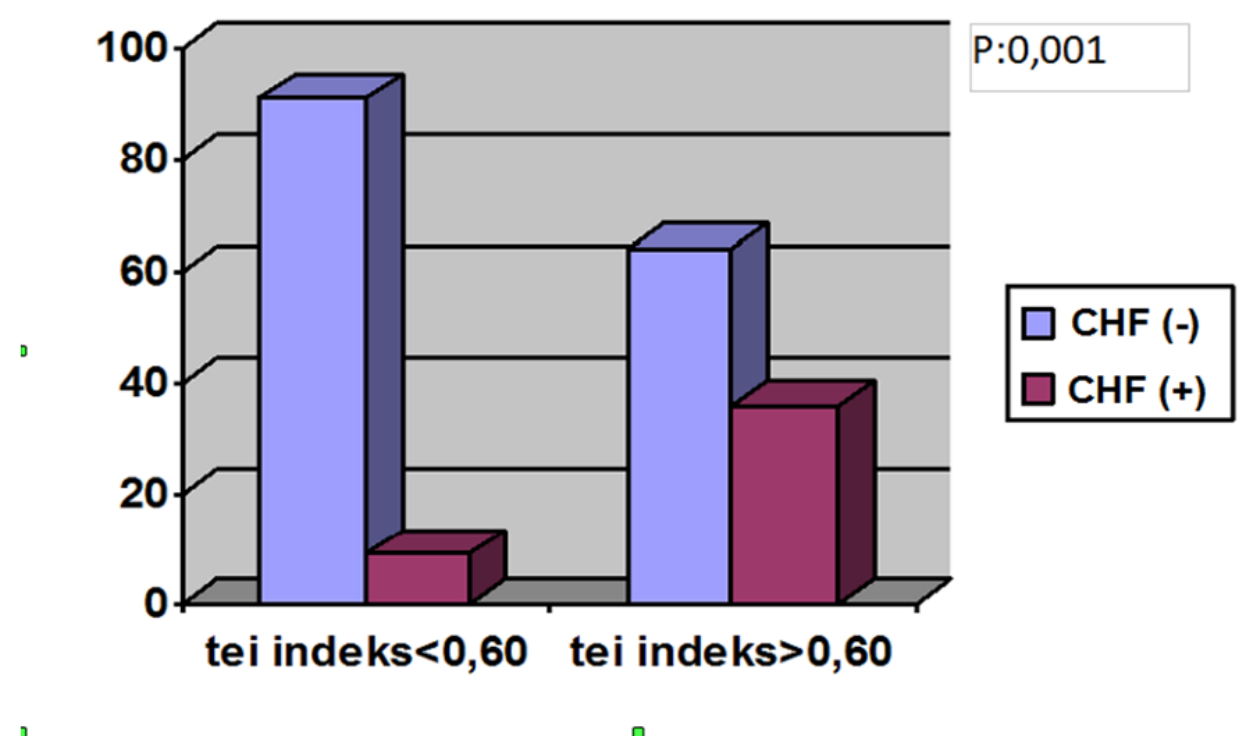

Figure 3: Comparison of the incidence of heart failure in patients with Tei index $<0.60$ and $\geq 0.60$.

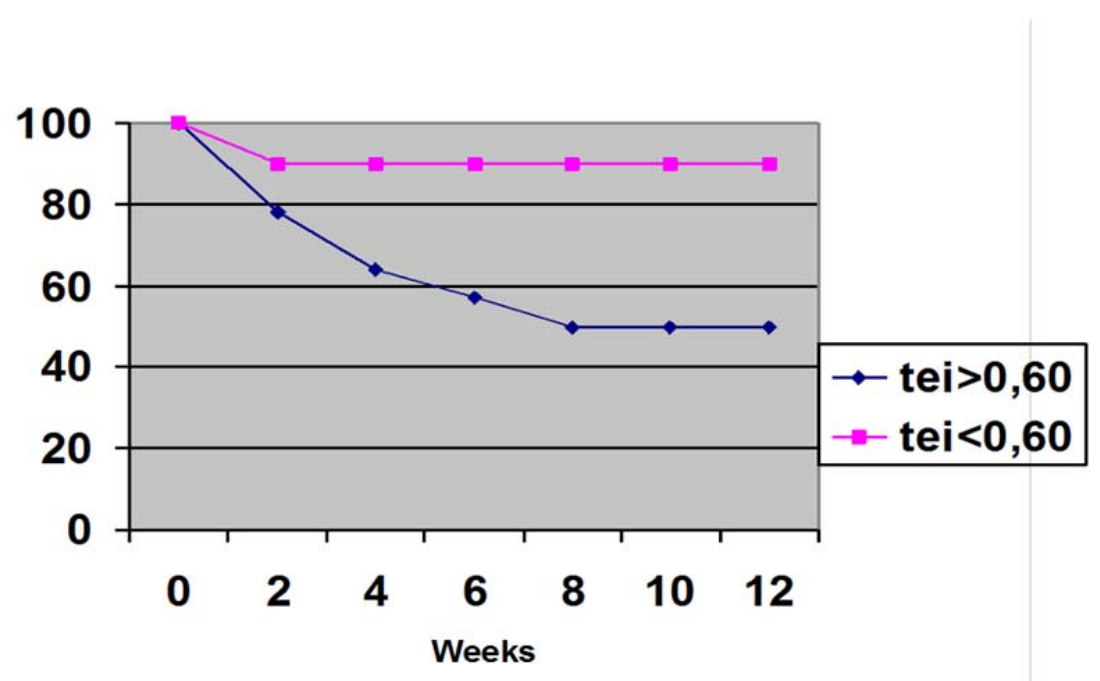

Figure 4: Tei indices by the percentage of cardiac event-free survival in the follow-up.

In the patient group with Tei index $<0.60$, the Tei index decreased from $0.49 \pm 0.01$ to $0.46 \pm 0.03$ within 3 months $(p=0.001)$. In the patient group with Tei index $\geq 0.60$, the Tei index decreased from $0.66 \pm 0.03$ to $0.60 \pm 0.04$ within 3 months $(p=0.001)$ (Figure 5). 


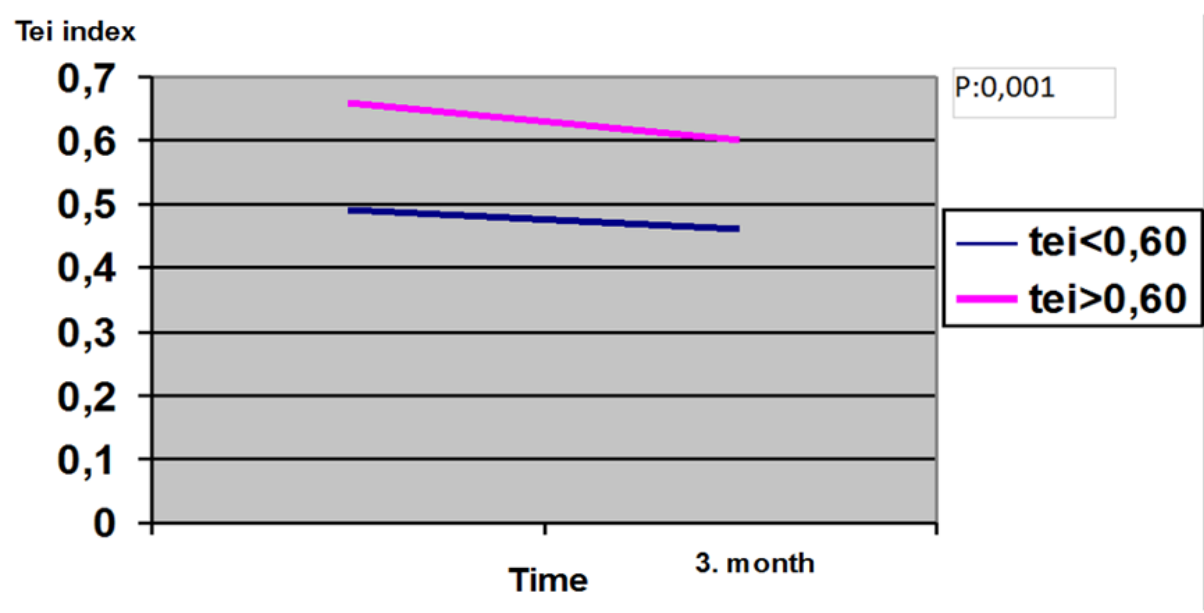

Figure 5: The change in Tei index during follow-up.

\section{Discussion}

Several studies have shown that the ejection fraction (EF) is a powerful guide in the selection of the appropriate treatment for patients who had a myocardial infarction (MI) and in the prediction of MI-related complications $[13,14]$. However, only the systolic functions can be evaluated with this classical evaluation method. Given that the systolic and diastolic dysfunctions frequently coexist, using a method that can assess both systolic and diastolic functions, rather than a parameter that evaluates them individually, may be more realistic in identifying a general cardiac dysfunction.

The Tei index has been shown to be a powerful, independent predictor of all-cause mortality in patients with MI. Adverse events are rarely seen in patients with a Tei index $<0.46$ [15]. The Tei index was identified as one of the independent determinants of the composite endpoint that include cardiac death, emergency cardiac transplantation as a result of decompensated CHF, and hospital admission in CHF patients with ischemic or dilated cardiomyopathy [16]. In patients with severe LV systolic dysfunction (LV EF $<30 \%$ ), those with higher Tei index have a higher overall incidence of clinical conditions such as death from any cause and need for urgent heart transplantation [17].

In one study, when Tei index values of 0.49 and above were determined as the threshold, cardiac dysfunction with combined systolic and diastolic dysfunction together was detected with $96 \%$ sensitivity and $86 \%$ specificity [18].

In one study, Tei indices on the first day of admission to the hospital and at the first year were higher in the patient group compared with the control group, and in patients who developed CHF or died compared with those who did not have CHF or survived [19]. Compared with patients who did not develop CHF, patients who developed CHF in the hospital after acute MI were found to have a significantly higher Tei index [20]. The multivariate regression analysis in that study showed that the Tei index values of 0.45 and above were the strongest independent 
determinant of CHF development in the hospital following acute MI [20].

In addition, the Tei index is an easy and reproducible measurement, as it is not affected too much by parameters such as age, heart rate, and preload.

Of the 50 patients included in our study, 4 died and 12 developed CHF symptoms. We found that Tei indices of patients who died or developed CHF were higher than those survived or did not develop CHF. In light of this finding, it may be suggested that the Tei index can be used as a predictor of mortality and CHF. In a study by Moller et al., one-year life expectancy was $37 \%$ among patients with a high Tei index while it was $89 \%$ among the patients with low Tei index [21]. In our study, the mean Tei index of the patients who died was 0.73 while it was 0.58 for those who survived. No death was observed during follow-up in the group with low Tei index, while a mortality rate of $14 \%$ was found in the group with high Tei index. In our study, the mean Tei index was found 0.59 in the patient group while it was 0.39 in the healthy control group; this difference was statistically significant.

In another study of 60 patients by Poulsen et al., the EFs, deceleration times, and Tei indices of acute anterior MI patients were examined on the 1st, 5th, 90th, and 360th days and the relationship between these parameters and cardiac events were investigated [22]. It was suggested that Tei index, just like EF, is a parameter that can be used in the evaluation of prognosis [22]. In previous studies, 0.60 was used as the threshold value for Tei index. We also separated the patients into two groups with the Tei index below or above 0.60 in our study, based on the echocardiographic measurements performed. The CHF developed at a rate of $35.7 \%$ in the group with high Tei index $(>0.60)$ while the rate was $9 \%$ in the group with low Tei index $(<0.60)$. These results are in line with the previous studies.

Of the 50 patients included in our study, 12 developed CHF (24\%) while 10 were found to have an EF <50\% (20\%). The symptoms of CHF developed in 2 patients although their systolic functions of the left ventricle were preserved (EF $>50 \%)$. The Tei indices were calculated as 0.69 and 0.70 for these two patients. This suggests that the symptoms of heart failure in these two patients were due to diastolic dysfunction.

In a study by Poulsen et al., echocardiographic examinations were performed on 64 patients being followed with acute MI diagnosis, and their EF and Tei index values were compared in terms of predicting the development of heart failure in the first week after the infarction. All of the patients who developed heart failure were found to have above-normal Tei index; 5 of these patients had left ventricular EF of more than $50 \%$. Despite the preservation of left ventricular systolic function in these 5 patients, the symptoms of heart failure developed due to diastolic dysfunction [23].

As a result of their study on 799 MI patients, Moller and colleagues found that the left ventricular systolic function 
was preserved in $33 \%$ of the patients who died while overall only $9 \%$ of the patients with preserved left ventricular function (Tei index $<0.45$ ) had died during follow-up [15]. The Tei index and a mitral flow deceleration time of less than $140 \mathrm{~ms}$ were found to be important in predicting cardiac mortality but there was no correlation between wall motion score index and mortality.

Moller et al. have shown that adverse events develop less in the patients with lower Tei index [15]. In parallel with this finding, the Tei index was found to be $0.71 \pm 0.01$ in the group of patients with major adverse cardiovascular events (MACE) while it was $0.55 \pm 0.07$ in the group of patients without MACE.

In a study based on simultaneous Doppler and hemodynamics evaluations, it has been shown that the value obtained by dividing IVRT by ejection time (ET) was closely related to left ventricular pressure drop during isovolumic relaxation period [24]. Based on changes in isovolumic time and ET, it can be said that the left ventricular dysfunction is predominant particularly in the early post-MI period; diastolic dysfunction becomes predominant at a later time due to the development of relaxation disorder in the left ventricle. This finding, which is based on changes in the Tei index, is consistent with previous studies. It has been shown in previous studies that systolic dysfunction develops early in the post-MI period while left ventricular relaxation is disturbed and diastolic dysfunction develops later with the development of compensatory hypertrophy during the process of left ventricular remodeling [25,26].

In fact, the patients in our study had left ventricular diastolic dysfunction early in the post-MI period. This is because we detected restrictive diastolic left ventricular filling patterns characterized by short deceleration time and high E/A ratio in the majority of patients, especially in the MACE-developing group. Previous studies support these findings $[27,28]$. Studies have shown that the development of restrictive left ventricular filling pattern is associated with increased left ventricular filling pressure and associated with left ventricular dilatation after MI, development of cardiac insufficiency, and cardiac death $[27,29,30]$. The fact that patients with a restrictive filling pattern in our study had higher Tei index values than those without restrictive filling pattern also indicate that such myocardial dysfunctions are accurately reflected by the Tei index values.

\section{References}

1. Williamson BD, Lim MJ, Buda AJ. Transient LV filling abnormalities (diastolic stunning) after acute MI. Am J Cardiol 66 (1990): 897-903.

2. Chenzbraun A, Keren A, Stern S. Doppler echocardiographic patterns of LV filling in patients early after acute MI. Am J Cardiol 70 (1992): 711-714.

3. Oh JK, Ding ZP, Gersh BJ, Bailey KR, Tajik AJ. Restrictive LV diastolic filling identifies patients with heart failure after acute MI. J Am Soc Echocardiogr 5 (1992): 497-503.

4. Popovic A, Neskovic N, Marinkovic J, Lee JC, Tan M, Thomas JD. Serial assessment of LV chamber stiffness after acute MI. Am J Cardiol 77 (1996): 361-364. 
5. Boudoulas H: Diastolic time: The forgotten dynamic factor. Implications for myocardial perfusion. Acta Cardiol 46 (1996): 61-71.

6. Brazier J, Cooper N, Buckberg G: The adequacy of subendocardial oxygen delivery: The interaction of determinants of flow, arterial oxygen content and myocardial oxygen need. Circulation 49 (1974): 968-977.

7. Tei C.New noninvazive index for combined systolic and diastolic ventricular function. J Cardiol 26 (1995): 135-136.

8. Poulsen SH, Jensen SE, Tei C, Seward JB, Egstrup K: Value of the Doppler index of myocardial performance in the early phase of acute myocardial infarction. J Am Soc Echocardiogr 13 (2000): 723-730.

9. Szymański P, Rezler J, Stec S, Budaj A. Long-term prognostic value of an index of myocardial performance in patients with myocardial infarction. Clin Cardiol 25 (2002): 378-383.

10. Bruch C, Schmermund A, Dagres N, Katz M, Bartel T, Erbel R. Tei-Index in coronary artery diseasevalidation in patients with overall cardiac and isolated diastolic dysfunction. Z Kardiol 91 (2002): 472-480.

11. shii M, Eto G, Tei C, Tsutsumi T, Hashino K, Sugahara Y, et al. Quantitation of the global right ventricular function in children with normal heart and congenital heart disease: a right ventricular myocardial performance index. Pediatr Cardiol 21 (2000): 416-421.

12. Zhang H, Otsuji Y, Matsukida K, Hamasaki S, Yoshifuku S, Kumanohoso $\mathrm{T}$, et al. Noninvasive differentiation of normal from pseudonormal/restrictive mitral flow using TEI index combining systolic and diastolic function. Circ J 66 (2002): 831-836.

13. St John Sutton M, Pfeffer MA, Plappert T, et al. Quantitative two-dimensional echocardiographic measurements are major predictors of adverse cardiovascular events after acute myocardial infarction. The protective effects of captopril. Circulation 89 (1994): 68-75.

14. Kober L, Torp-Pedersen C, Jorgensen S, Eliasen P, Camm AJ. Changes in absolute and relative importance in the prognostic value of left ventricular systolic function and congestive heart failure after acute myocardial infarction. TRACE Study Group. Trandolapril Cardiac Evaluation. Am J Cardiol 81 (1998): 1292-1297.

15. Moller JE, Egstrup K, Kober L, Poulsen SH, Nyvad O, Torp-Pedersen C. Prognostic importance of systolic and diastolic function after acute myocardial infarction. Am Heart J 145 (2003): 147-153.

16. Ito T, Suwa M, Kobashi A, Hirota Y, Kawamura K. Ratio of pulmonary venous to mitral A velocity is a useful marker for predicting mean pulmonary capillary wedge pressure in patients with left ventricular systolic dysfunction. J Am Soc Echocardiogr 11 (1998): 961-965.

17. Chen C, Rodriguez L, Lethor JP, et al. Continuous wave Doppler echocardiography for noninvasive assessment of left ventricular $\mathrm{dP} / \mathrm{dt}$ and relaxation time constant from mitral regurgitant spectra in patients. $\mathrm{J}$ Am Coll Cardiol 23 (1994): 970-976.

18. McKay RG, Pfeffer MA, Pasternak RC, et al. Left ventricular remodeling after myocardial infarction: a corollary to infarct expansion. Circulation 74 (1986): 693-702.

19. Erlebacher JA, Weiss JL, Eaton LW, Kallman C, Weisfeldt ML, Bulkley BH. Late effects of acute infarct dilation on heart size: a two dimensional echocardiographic study. Am J Cardiol 49 (1982): 1120-1126. 
20. Hammermeister KE, DeRouen TA, Dodge HT. Variables predictive of survival in patients with coronary disease. Selection by univariate and multivariate analyses from the clinical, electrocardiographic, exercise, arteriographic, and quantitative angiographic evaluations. Circulation 59 (1979): 421-430.

21. Moller JE, Sondergaard E, Poulsen SH, Egstrup K. The Doppler echocardiographic myocardial performance index predicts left-ventricular dilation and cardiac death after myocardial infarction. Cardiology 95 (2001): 105-111.

22. Poulsen SH, Jensen SE, Nielsen JC, Moller JE, Egstrup K. Serial changes and prognostic implications of a Doppler-derived index of combined left ventricular systolic and diastolic myocardial performance in acute myocardial infarction. Am J Cardiol 85 (2000): 19-25.

23. Poulsen SH, Jensen SE, Tei C, Seward JB, Egstrup K. J Value of the Doppler index of myocardial performance in the early phase of acute myocardial infarction. J Am Soc Echocardiogr 13 (2000): 723-730.

24. Tei C, Nishimura RA, Soward JB, Tajik AJ. Noninvasive Doppler-derived myocardial performance index: correlation with simultaneous measurements of cardiac catheterization measurements. J Am Soc echocardiogr 10 (1997): 169-178.

25. Korup E, Dalsgaard D, Nyvad O, Jensen TM, Berning J. Comparison of degrees of left ventricular dilation within three hours and up to six days after onset of first acute myocardial infarction. Am J Cardiol 80 (1997): 449-453.

26. Raya TE, Gay RG, Lancaster I, Aguirre M, Moffett C. Serial changes in left ventricular relaxation after and chamber stiffness after large myocardial infarction in rats. Circulation 77 (1988): 1424-1431.

27. Oh JK, Dine ZP, Gerse BJ, et al. Restrictive left ventricular diastolic filling identifes patients with heart failure after acute myocardial infarction. J Am Soc Echocardiography 5 (1992): 497-503.

28. Popovic AD, Neskovic AN, Marinkovic J, Lee JR, Tan M. Serial assessement of left ventricular chamber stiffness after acute myocardial infarction. Am J Cardiol 77 (1996): 361-364.

29. Censano G, Bolognase L, Carabba N, Buonamici P, Santoro GM, Antoniucci D, Pazzini PF, et al. Doppler derived mitral deceleration time. An early strong predictor of left ventricular remodelling after reperfused anterior acute myocardial infarction. Circulation 99 (1999): 230-236.

30. Nijland F, Kamp O, Karreman AJ, Benige MJ, Visser JA. Prognostic implications of restrictive left ventricular filling in acute myocardial infarction: a serial Doppler echocardiographic study. J Am Coll Cardiol 30 (1997): 1618-1624.

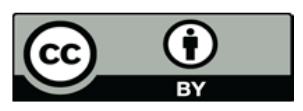

This article is an open access article distributed under the terms and conditions of the $\underline{\text { Creative Commons Attribution (CC-BY) license 4.0 }}$ 